This item was submitted to Loughborough's Research Repository by the author.

Items in Figshare are protected by copyright, with all rights reserved, unless otherwise indicated.

\title{
Analysis of cooling channels performance
}

PLEASE CITE THE PUBLISHED VERSION

http://dx.doi.org/10.1080/0951192042000237528

VERSION

SMUR (Submitted Manuscript Under Review)

LICENCE

CC BY-NC-ND 4.0

\section{REPOSITORY RECORD}

Norwood, Andrew J., Phill M. Dickens, Rupert C. Soar, Russell A. Harris, G. Gibbons, and R. Hansell. 2019. "Analysis of Cooling Channels Performance". figshare. https://hdl.handle.net/2134/4649. 
This item was submitted to Loughborough's Institutional Repository (https://dspace.lboro.ac.uk/) by the author and is made available under the following Creative Commons Licence conditions.

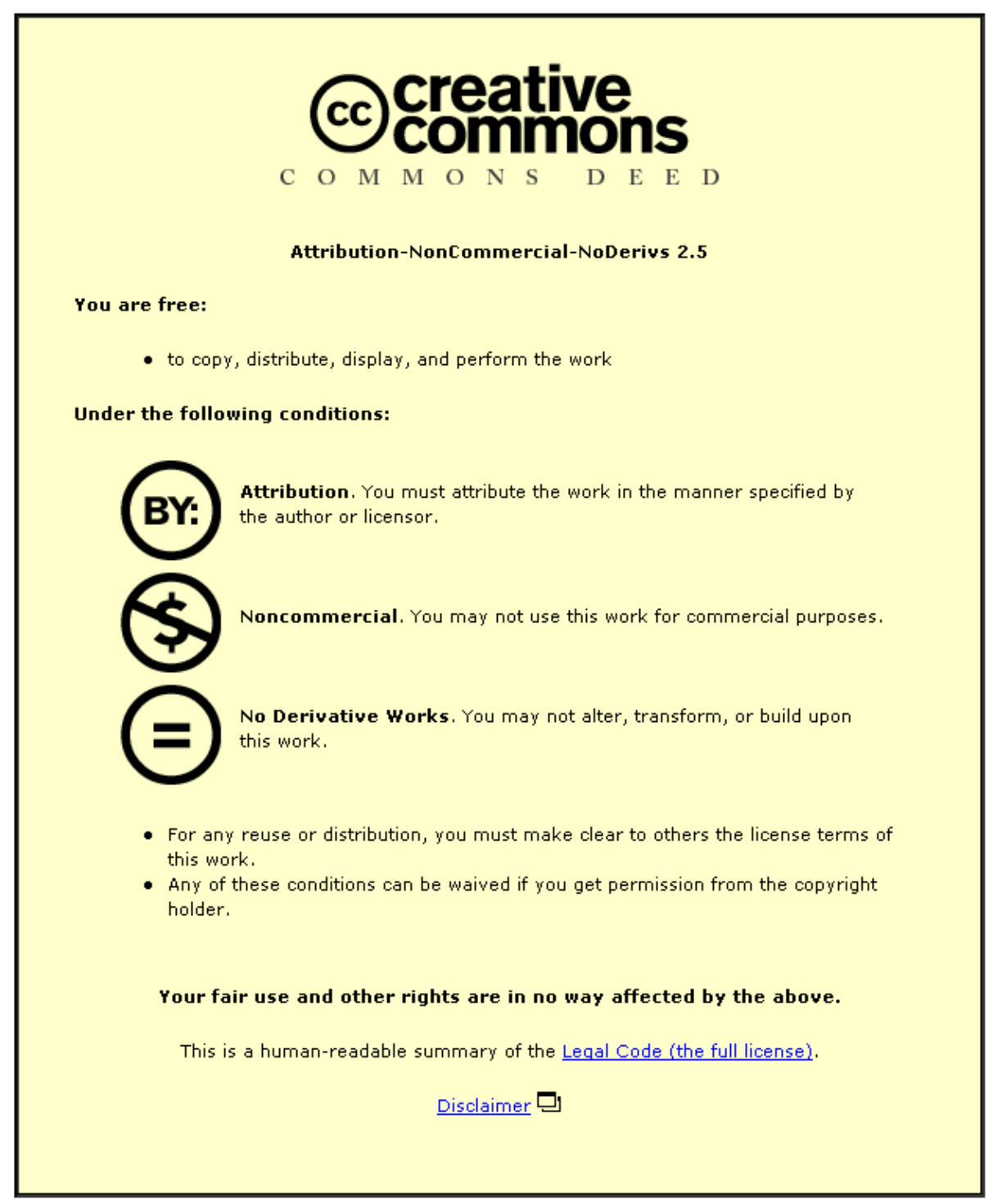

For the full text of this licence, please go to: http://creativecommons.org/licenses/by-nc-nd/2.5/ 


\title{
Analysis of Cooling Channels Performance for Cycle Time Reduction Using Rapid Manufacturing Techniques and Computational Fluid Dynamic Analysis
}

\author{
A. J. Norwood ${ }^{1 *}$, P. M. Dickens ${ }^{1}$, R. C. Soar ${ }^{1}$, R. Harris ${ }^{1}$ G. Gibbons ${ }^{2}$, R. Hansell ${ }^{2}$ \\ ${ }^{1}$ The Rapid Manufacturing Research Group, Wolfson School of Mechanical and Manufacturing \\ Engineering, Loughborough University, Leicestershire, LE11 3TU, UK \\ ${ }^{2}$ Warwick Manufacturing Group, Advanced Technology Centre, University of Warwick, Coventry, \\ CV4 7AL, UK
}

\begin{abstract}
The die casting industry is under increasing pressure to improve production rates to enable greater productivity. The potential to decrease the cycle time is of great significance. A small reduction in the cycle time can significantly improve production rates. Employing conformal cooling channels allows improvements to be made to die performance through the reduction of solidification times. The paper reviews simulated solidification results from a traditional cooling channel design and a conformal cooling channel design. The paper continues by describing the construction of bonded laminate insert with integrated cooling channels. Casting trials were conducted using the inserts to validate the simulated results. Work to date has demonstrated the ability to manufacture laminate inserts quickly, the accuracy of computational fluid dynamics and the importance of conformal cooling design.
\end{abstract}

Keywords: Computational fluid dynamics, computer simulation, rapid tooling, laminate tooling, pressure die-casting, conformal cooling, cycle time reduction 


\section{INTRODUCTION}

The cooling of mould tools is crucial to the performance of tooling, it effects both production rates and component quality [1].

The rapid prototyping industry employs layer methods of manufacturing that allow virtually any geometry to be physically constructed [2]. Due to this versatility, engineers are able to design and build complex components with internal features such as conformal cooling channels. Conformal cooling is achieved by creating a cooling channel that follows the exact contours of the mould cavity. By having the cooling channels uniformly located around the cavity, the risk of hot spots is virtually eliminated since the die is uniformly cooled this has been reported to produce less stressed parts in injection moulding. The increased effect of conformal cooling also helps to reduce cycle times, which in turn results in increased production rates. Conformal cooling lines of high complexity can be created [3]. Currently tooling is cooled through straight interconnecting channels. This traditional method is less than optimal because the passages can only be directed at right angles and cannot be optimally placed next to those strategic areas that need cooling. The result is a slower cycle time for the production of parts.

Various methods exist to produce tools containing conformal cooling, such as laser sintering, spray metal tooling [4], laser caving, wiba \& keltool etc. However, laminate tooling could offer higher strength and toughness than the materials currently used in traditional layered manufacturing [5]. Laminate tooling is a typical layer by layer manufacturing process requiring a 3D STL CAD file which is then sliced into layers. This sliced data is used to laser cut the individual laminates form sheet tool steel, these are then brazed together to form a die. The die surfaces are finished by either electrical discharge machining or high speed machining to remove the stepping effect created by layer manufacturing. Laminate tool manufacture allows a die to be constructed from die steel with the benefit of integrated conformal cooling as appose to a solid H13 die where only straight cooling channels can be machined.

Software such as MAGMASOFT ${ }^{\circledR}$ now offer the die designer the ability to model tools and predict areas of concern and calculate mould fill times. The introduction of conformal cooling channels within tool design reduces the constraints / compromises made regarding cooling, as they can be placed exactly where required [6]. 


\section{AIMS AND OBJECTIVES}

It is the intention of this research to explore the benefits conformal cooling may have on aluminium (LM24) pressure die-casting cycle times.

The main objectives of this research were:

(a) to conduct a simulation to compare a traditional cooling design against a conformal cooling design.

(b) to validate the simulation results by conducting die casting trials.

This paper presents the results from the first part of this effort, which was to make a direct comparison between simulated solidification times of a traditionally cooled die insert and a conformally cooled die insert. MAGMASOFT ${ }^{\circledR}$ simulation software was employed for this task. The results were then verified by conducting casting solidification trials using traditionally and conformally cooled insets. The casting used for the case study, shown in Figure 1 was chosen as it is representative of a typical commercial aluminium die cast tool that would be run at high production speeds. The tool was supplied by Dyson Ltd through Kemlows Diecasting Products Ltd.

Future research will consider different cooling channel geometry and the effect that complex die geometries have on cooling performance employing both simulation and insert manufacture to verify results.

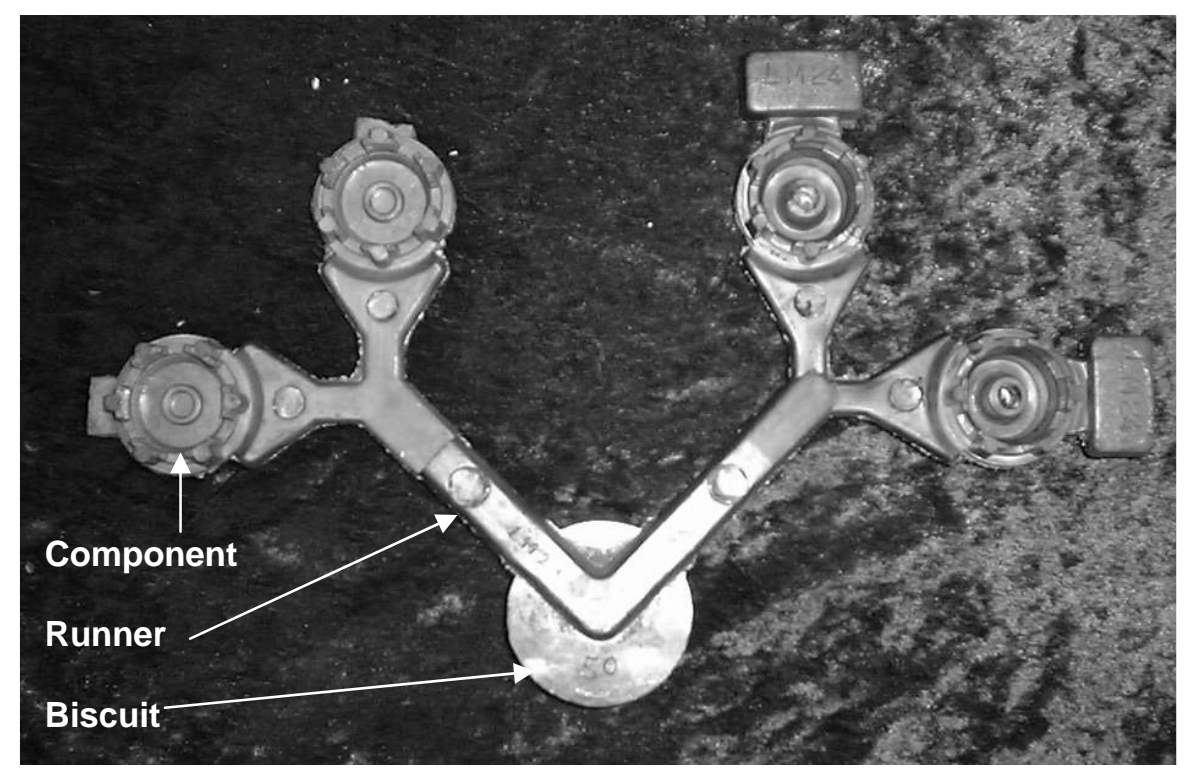

Figure 1 Cast aluminium (LM24) clutch housing component 
Two tests were designed to evaluate the efficiency of traditional cooling and conformal cooling. The biscuit area shown in Figure 1 was chosen as the focus of the research. This area of a tool is typically more affective by wear, temperature, pressure etc. It is also the last area to solidify since it feeds aluminium to the casting as it solidified reducing shrinkage. It was the intention to show that increasing the amount of cooling in the runner system could reduce solidification time and in turn, reduce the cycle time.

\subsection{Conformal Cooling Design}

The initial stages was the design of the conformal cooling channel that followed the profile of the runner in the biscuit area. A 3D STL CAD model was created using Materialise Magics software of the inserts, one traditional cooled and the other conformal cooled as shown in Figure 2
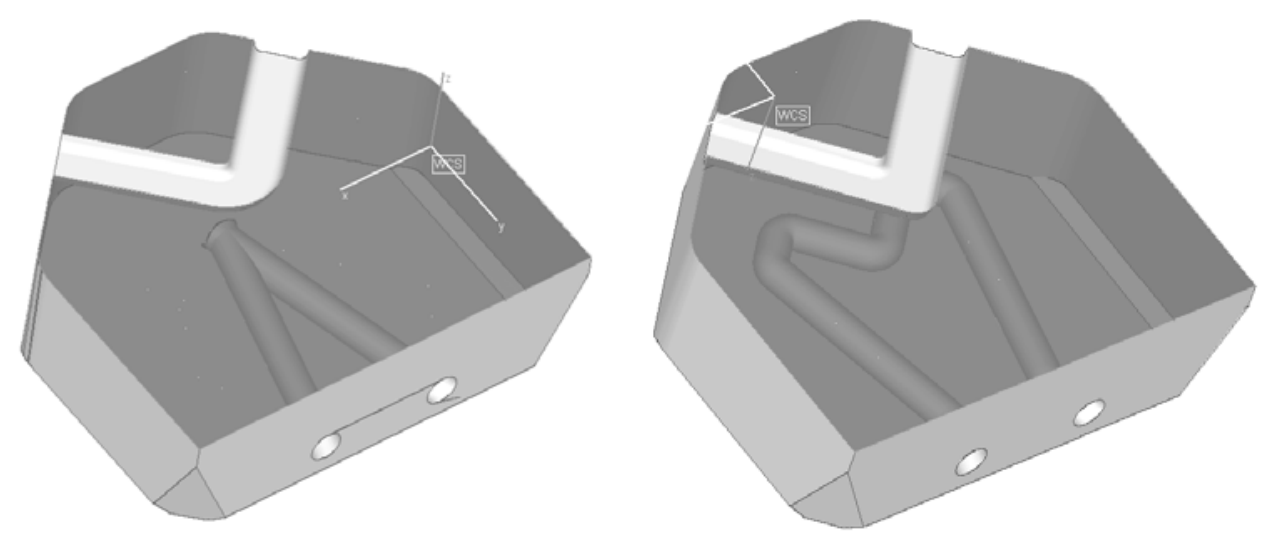

Figure 2 Biscuit and runner insert design for traditional cooling (left) and conformal cooling (right)

The diameter of the cooling lines in both were set at $10 \mathrm{~mm}$. The conformal cooling channel design shown in Figure 2 had a ' $M$ ' profile following the runner and biscuit area. By introducing a larger cooled area in the biscuit region (11/2 times larger) it was envisaged that the inserts cooling efficiency would increase due to the increased surface area of the cooling channel and water volume. 


\subsection{Magmasoft Simulation}

Simulation was used to determine if a difference in time to solidification could be determined between the two cooling designs. Analysis of the die was conducted using MAGMASOFT ${ }^{\circledR}$ software.
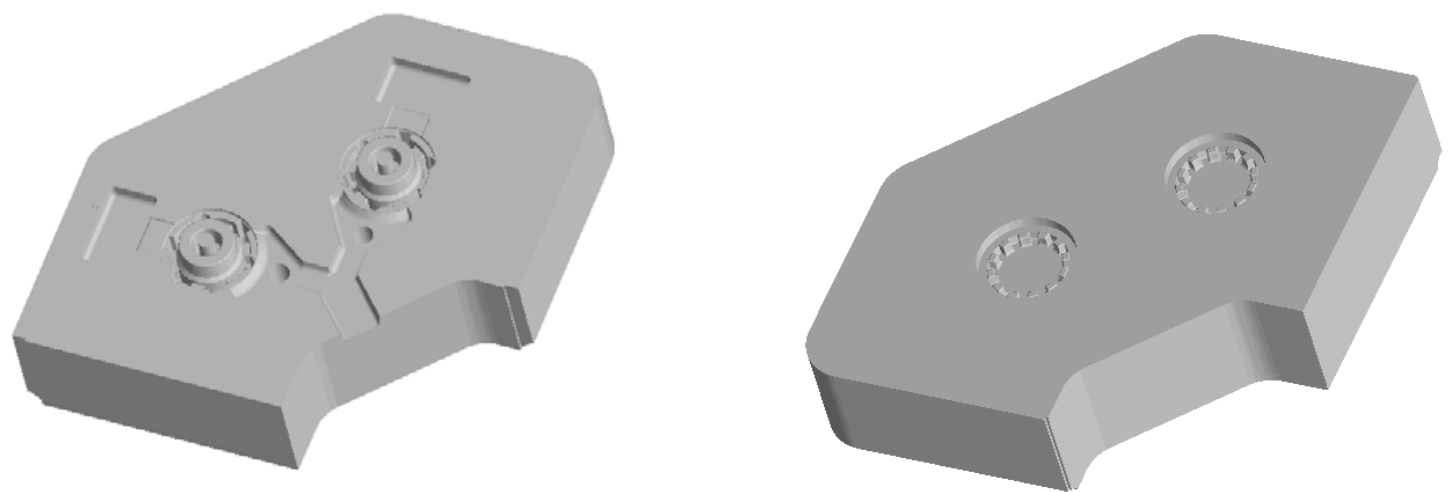

Figure 3 Male and female STL CAD of inserts

In order to conduct the simulation the remainder of the tool inserts were modelled shown in Figure 3. All the STL CAD files were then combined, one with traditional cooling and the other with conformal cooling shown in Figure 4. These were then imported into the MAGMASOFT ${ }^{\circledR}$ pre-processor.
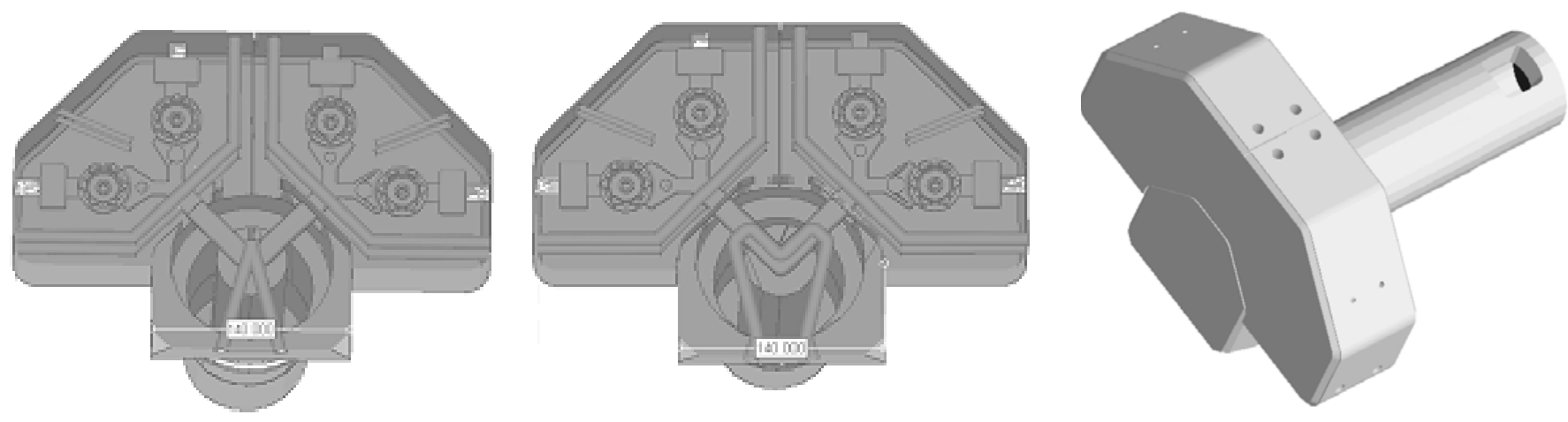

Figure $43 D$ CAD models of the inserts and shot sleeve used for simulation

Half the model was removed as the die was symmetrical allowing a reduction in processing time, the model was then meshed. Die cycling temperature and water cooling were simulated. Figure 5 shows ten theoretical thermocouples that were positioned in the model, starting at the plunger tip spaced evenly through the insert, casting and cooling channel. The simulation was cycled 10 times to achieve 'near' steady state. The temperature of each thermocouple was recorded on the $11^{\text {th }}$ cycle in a graphical format showing the time taken for the component to 
solidify. Approximately 8.5 temperature readings were recorded / thermocouple / second. Thermocouple 1 was located at the end of the plunger tip stroke, thermocouple 2, 3, 4 were located in the biscuit area of the casting, thermocouple 5, 6, 7, 8 were located in the insert and thermocouple 9, 10 were located in the cooling channel.
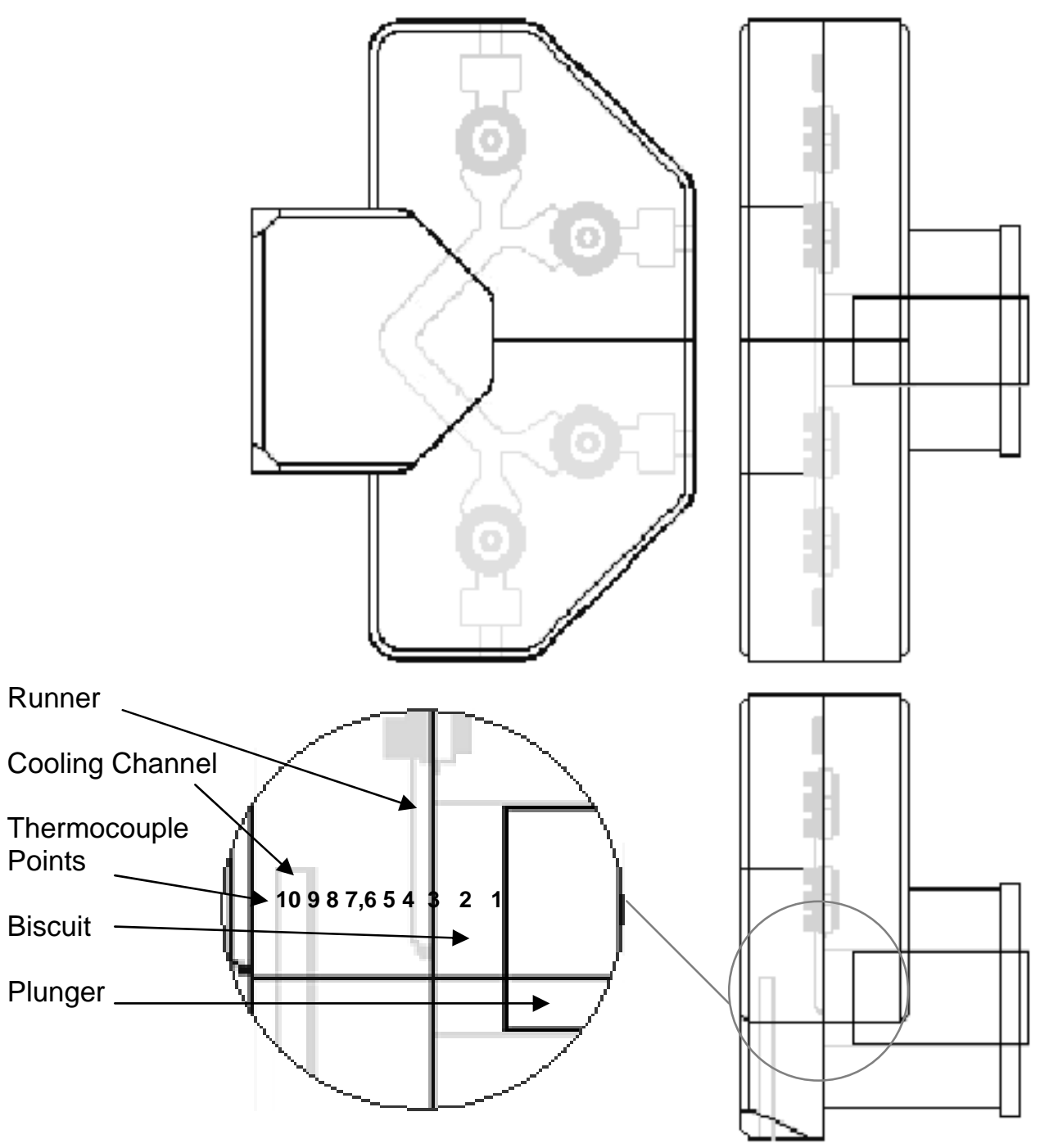

Figure 5 Section through the tool showing the location of thermocouple points.

\subsection{Casting Validation}

Tool inserts were manufactured and ran at production rates to validate the simulated solidification results. The aim was to reduce the solidification time to achieve a burst biscuit. A burst biscuit is where a casting has had insufficient time to fully solidify shown in Figure 6. In pressure die casting the biscuit is situated at the start of the runner system shown in Figure 7. It feeds the casting and is usually the thickest part, making it the last area to solidify. By decreasing the solidification time it is possible to create what is called a "burst biscuit" which is where molten metal in the centre of the biscuit forces its way through a skin of solidified material. By achieving a burst biscuit the minimum amount of time to solidification can be 
determined. The lower the solidification time the faster the cycle time and productivity, as shown in Figure 8.

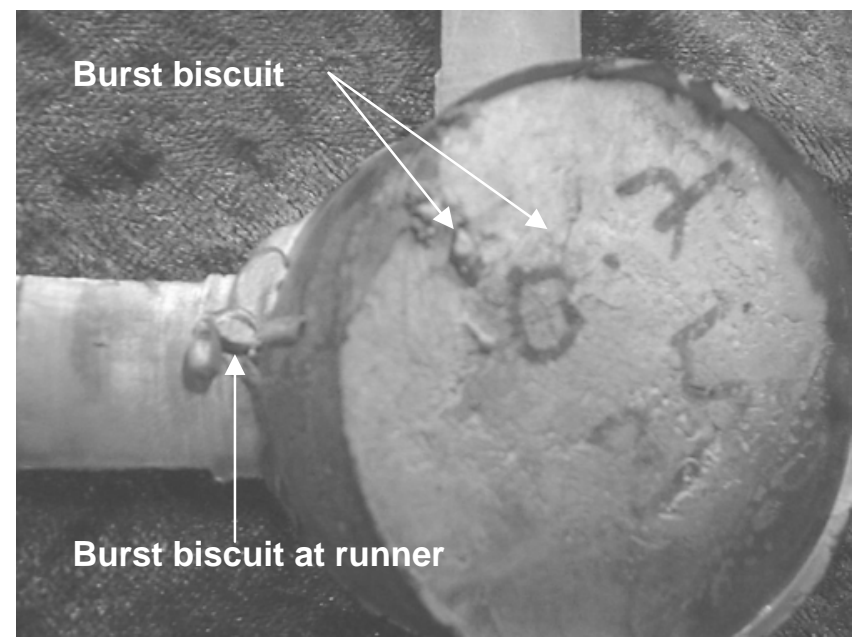

Figure 6 Burst biscuit

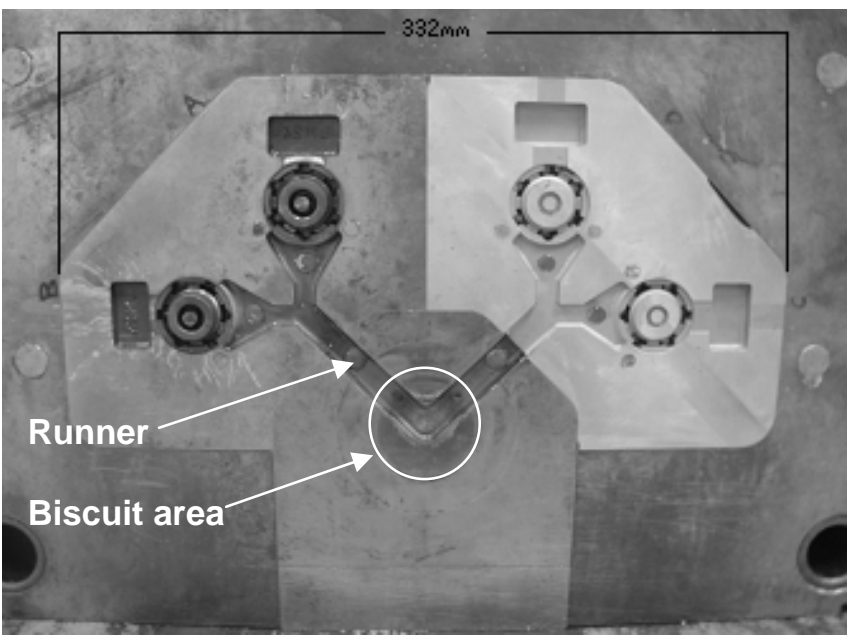

Figure 7 Insert location

\begin{tabular}{|c|c|c|c|c|c|c|c|c|}
\hline $\begin{array}{l}\text { Operator } \\
\text { Starting cycle } \\
1-2 \text { sec }\end{array}$ & $\begin{array}{l}\text { Die } \\
\text { Close } \\
\text { 1sec }\end{array}$ & $\begin{array}{l}\text { Ladling } \\
5-8 \text { sec }\end{array}$ & $\begin{array}{l}\text { Injection } \\
1 \text { sec }\end{array}$ & $\begin{array}{l}\text { Solidification } \\
3 \text { sec }\end{array}$ & & $\begin{array}{l}\text { Die Open } \\
3 \text { sec }\end{array}$ & $\begin{array}{l}\text { Ejection } \\
3 \mathrm{sec}\end{array}$ & $\begin{array}{l}\text { Release } \\
\text { Agent } \\
3 \text { sec } \\
\end{array}$ \\
\hline $\begin{array}{l}\text { Operator } \\
\text { Starting cycle } \\
1-2 \text { sec }\end{array}$ & $\begin{array}{l}\text { Die } \\
\text { Close } \\
\text { Isec }\end{array}$ & $\begin{array}{l}\text { Ladling } \\
5-8 \text { sec }\end{array}$ & $\begin{array}{l}\text { Injection } \\
1 \text { sec }\end{array}$ & $\begin{array}{l}\text { Solidification } \\
\text { ? sec }\end{array}$ & $\begin{array}{l}\text { Die Open } \\
3 \text { sec }\end{array}$ & $\begin{array}{l}\text { Ejection } \\
3 \mathrm{sec}\end{array}$ & $\begin{array}{l}\text { Release } \\
\text { Agent } \\
3 \mathrm{sec}\end{array}$ & \\
\hline
\end{tabular}

Figure 8 Typical cycle time of the die 


\subsection{Laminate Die Insert Manufacture}

In order to manufacture the laminated biscuit/runner inserts shown in Figure 10 the 3D STL CAD designs required slicing to generate 2D DXF CAD data. A subroutine in Delcam's PowerShape 3D package enabled automatic slicing of the 3D inserts. The files were sliced with in layer thickness of $1 \mathrm{~mm}$, the thickness of the steel sheet. The software produced a total of $902 \mathrm{D}$ DXF profiles.

The profiles defined each cutting path of the laser, to produce the individual laminates. The cutting paths were transferred directly to a 1200 Watt Photon Versa $\mathrm{CO}_{2}$ continuous gas laser cutter where the $\mathrm{H} 13$ steel laminates were cut. The laminates were then grit blasted with a nickel alloy abrasive at $620 \mathrm{kPa}$ to remove burrs, oxide layer and then degreased with isopropyl alcohol $\left(\left(\mathrm{CH}_{3}\right)_{2} \mathrm{CHOH}\right)$. The laminates were bonded using Amdry 936 supplied by Sulzer Metco in powder form [Table 1]. The laminates were placed and each joint coated with Amdry 936 in a purpose built fixture to prevent excessive movement during the brazing process. The nickel braze was used due to its high melting temperature and ease of machinability.

\begin{tabular}{|l|c|}
\hline & AMDRY 936 \\
\hline Recommended braze temperature & $970-1010^{\circ} \mathrm{C}\left(1775-1850^{\circ} \mathrm{F}\right)$ \\
\hline Recommended gap size & $0.013 \mathrm{~mm}-0.1 \mathrm{~mm}\left(0.0005^{\prime \prime}-0.004^{\prime \prime}\right)$ \\
\hline Composition & $\begin{array}{c}\text { Nickel Balance. - 19 Magnesium - 6Silicon - 1Boron - } \\
\text { 4Copper - 0.03Rhenium }\end{array}$ \\
\hline
\end{tabular}

Table 1 Braze details

The inserts were brazed in a furnace with an inert Argon atmosphere. The furnace was purged with Argon at $100 \mathrm{kPa}$ and $30 \mathrm{l} / \mathrm{m}$ flow for 20 minutes prior to the start of the brazing cycle shown in Figure 9. The Argon was then reduced to $100 \mathrm{kPa}$ and $20 \mathrm{l} / \mathrm{m}$ flow when the brazing process commenced. The first temperature hold at $150^{\circ} \mathrm{C}$ for 15 minutes was to allow solvents or water in the braze and furnace to outgas. This helped to prevent porosity in the braze and allowed time for the atmosphere to replenish. The second hold at $540^{\circ} \mathrm{C}$ for fifteen minutes allowed organics in the braze sufficient time to become gaseous and to be pumped out and again time for the inert atmosphere to return. At $960^{\circ} \mathrm{C}$ there was a stabilisation hold for ten minutes. The temperature was then held at $1010^{\circ} \mathrm{C}$ for one hour to allow sufficient time for the alloy to melt and flow into the joint. 


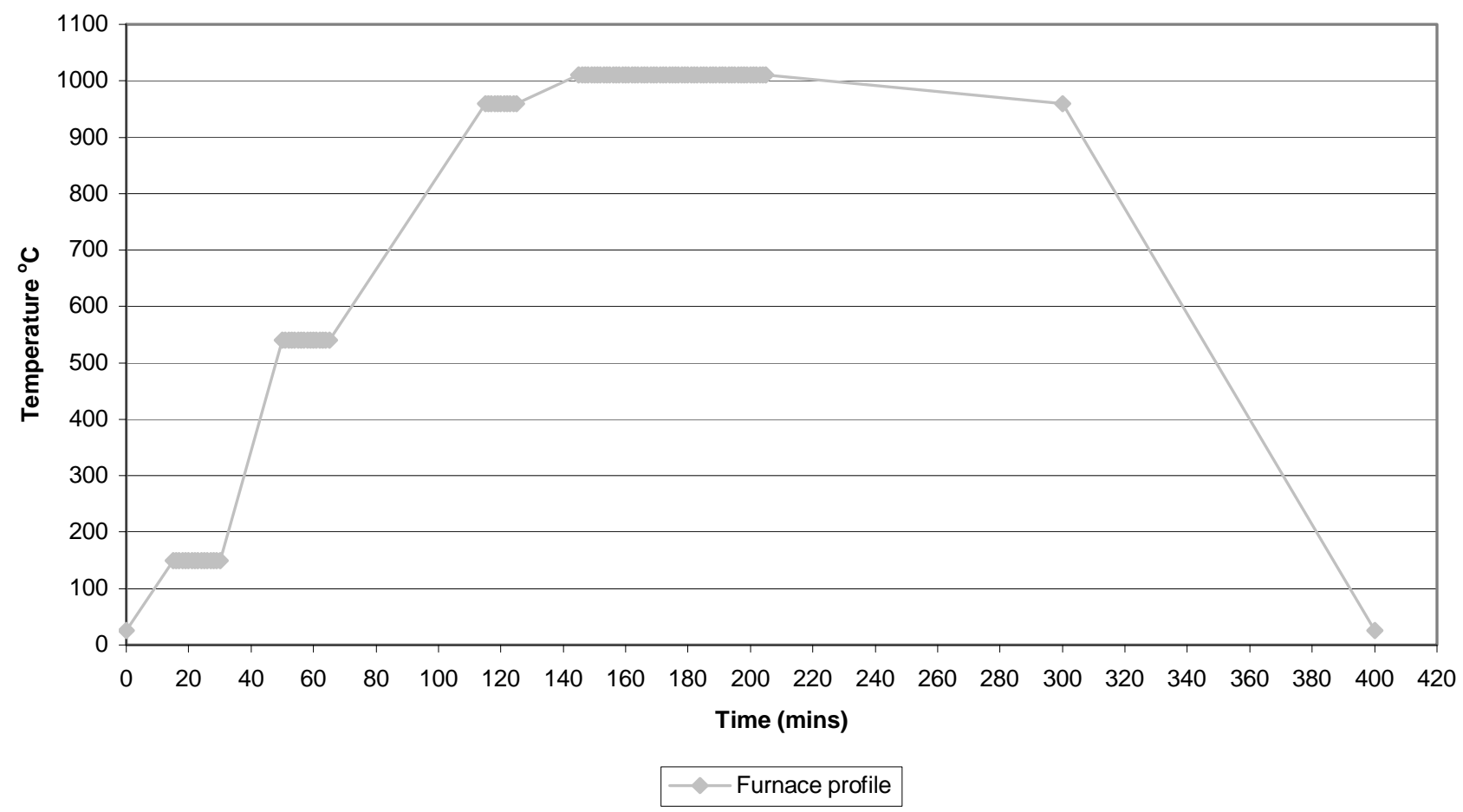

Figure 9 Heating and cooling profile of the brazing process

The inserts were allowed to cool in the furnace below the solids temperature of the braze at approximately $960^{\circ} \mathrm{C}$ at which point they were removed from the furnace and air quenched. Figure 10 shows the traditional insert after final machining of the exterior, runner and ejector holes.

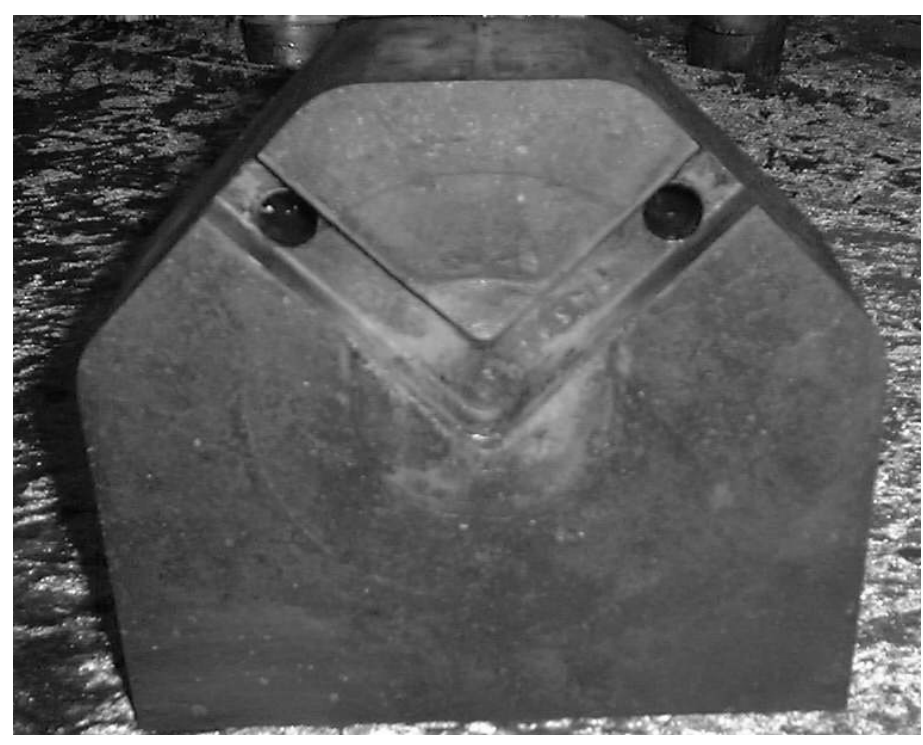

Figure 10 Insert after machining 


\subsection{Casting Procedure}

The experiments involved a series of casting trials which were conducted at production speeds to maintain a representative die temperature.

The cooling channels were tested to ensure no leaks were present. This was achieved by simply blocking the outlet of the water channel, connecting the inlet to mains water (400 $\mathrm{kPa})$ and checking for leaks. No leaks were detected.

The casting was conducted on a Frech 125 DAK SDV cold chamber die-casting machine which was modified to allow the solidification time to be reduced below 3 Seconds. This is not a standard procedure due to the danger involved with opening a die whilst aluminium is potentially molten. To safe guard against injury the area was sealed off and machine guards put in place.

The die casting machine cycle was set up as previously shown in Figure 8. The cycle time was set at approximately 170 shots per hour (21 second cycle) with a solidification time of 3 seconds. The die was initially heated with a gas lance for $1 \frac{1}{2}$ hours and then 150 shots cast to achieve the dies working temperature of $200^{\circ} \mathrm{C}-250^{\circ} \mathrm{C}$. Thereafter, samples were taken every 10 shots and the cooling time for each shot recorded. After every 10 shots the cooling time was decreased by 0.1 of a seconds until there were signs of a biscuit burst. 


\subsection{Simulation Results}

Thermal images show the rate at which solidification occurs in Figure 11 \& Figure 12. Both the traditionally cooled and conformally cooled thermal image shows the majority of the casting had solidified after 2 seconds with the exception of the biscuit area. The centre of the traditionally cooled biscuit takes approximately 10 seconds to fully solidify in comparison to 9 seconds for the conformally cooled image.

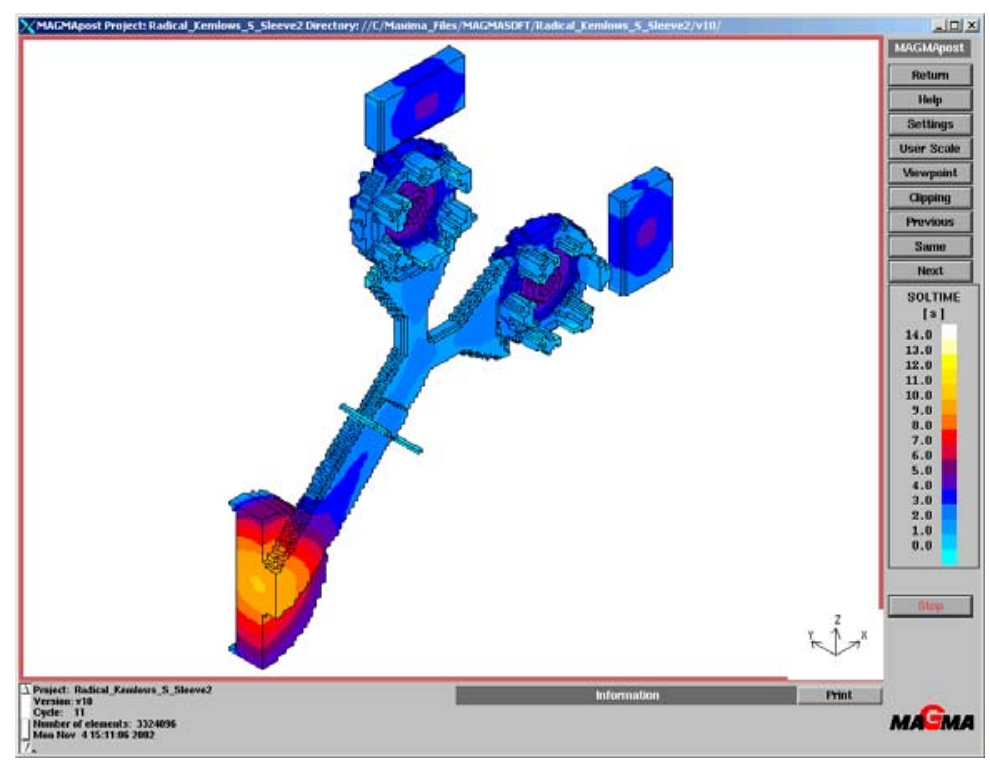

Figure 11 Traditionally cooled solidification time

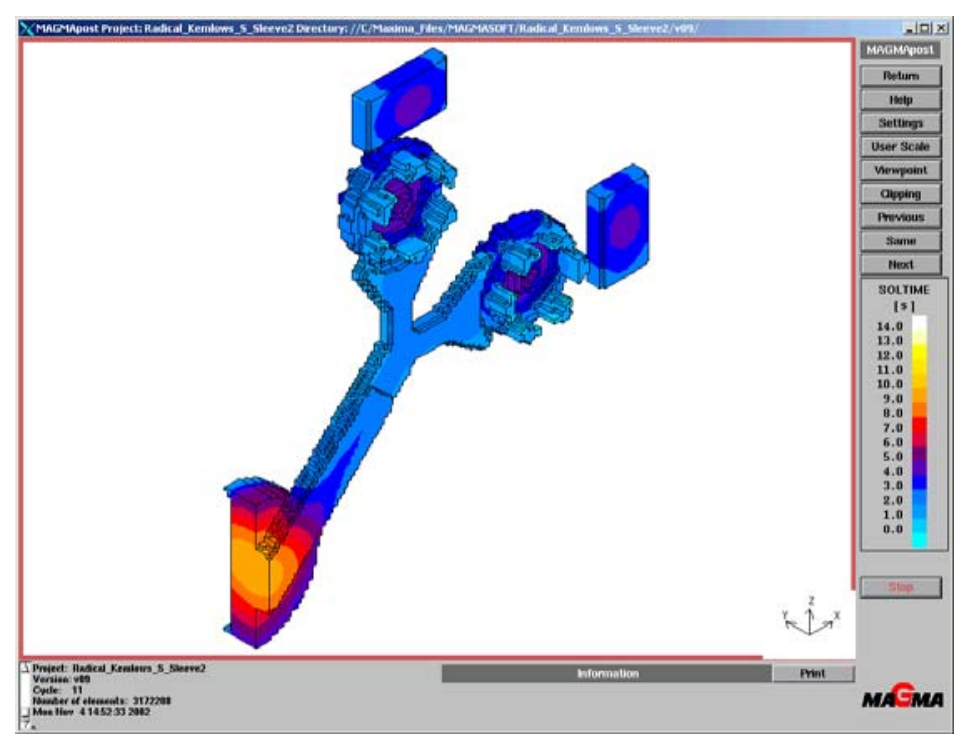


Figure 12 Conformal cooling solidification time

This is confirmed when comparing the raw data from thermocouple points 2,3 \& 4 that were situated in the biscuit and runner. Aluminium LM24 solidifies between $520^{\circ} \mathrm{C}$ and $580^{\circ} \mathrm{C}$ which is where crystallisation begins and ends, this is termed latent heat of fusion shown in Figure 13. Thermo couple 2 and 3 are located in the centre of the biscuit, solidification begins after 1 second and ends after approximately 8 seconds. Thermocouple 4 is located at the edge of the runner near the die surface and is naturally is the first area to solidify, starting at 0.3 of a second and finishing at approximately 5 seconds. Figure 13 shows there is no significant difference between the traditionally cooled (TC) and conformally cooled (CC) insert solidification times.

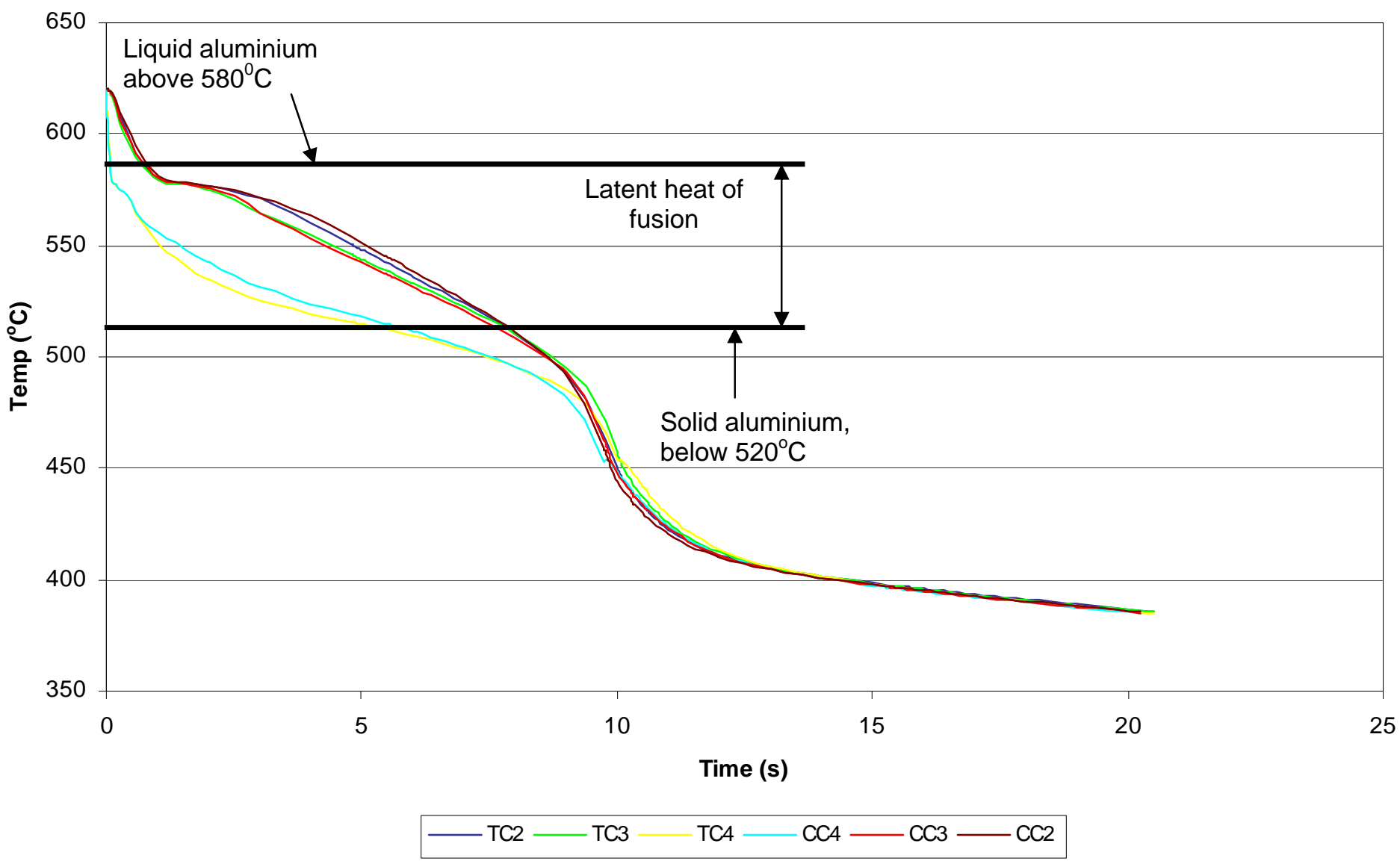

Figure 13 Traditional cooling (TC) verses conformal cooling (CC) (thermocouples 2-4)

Thermocouples 5,6,7 \& 8 were situate in the insert and as one would expect the closer to the die surface the thermocouple was, the greater the temperature recorded. This can be see in Figure 14 where traditionally cooled thermocouple 5 (TC5) is approximately $55^{\circ} \mathrm{C}$ hotter than traditionally cooled thermocouple 8 (TC8) the same is true of conformally cooled thermocouple 5 and 8 (CC5 \& CC8). 
When comparing the traditional and conformal thermocouple points it can be seen that the conformally cooled insert is typically $20^{\circ} \mathrm{C}$ cooler than that of the traditionally cooled insert for each thermocouple location [Figure 14, TC7 and CC7 for example].

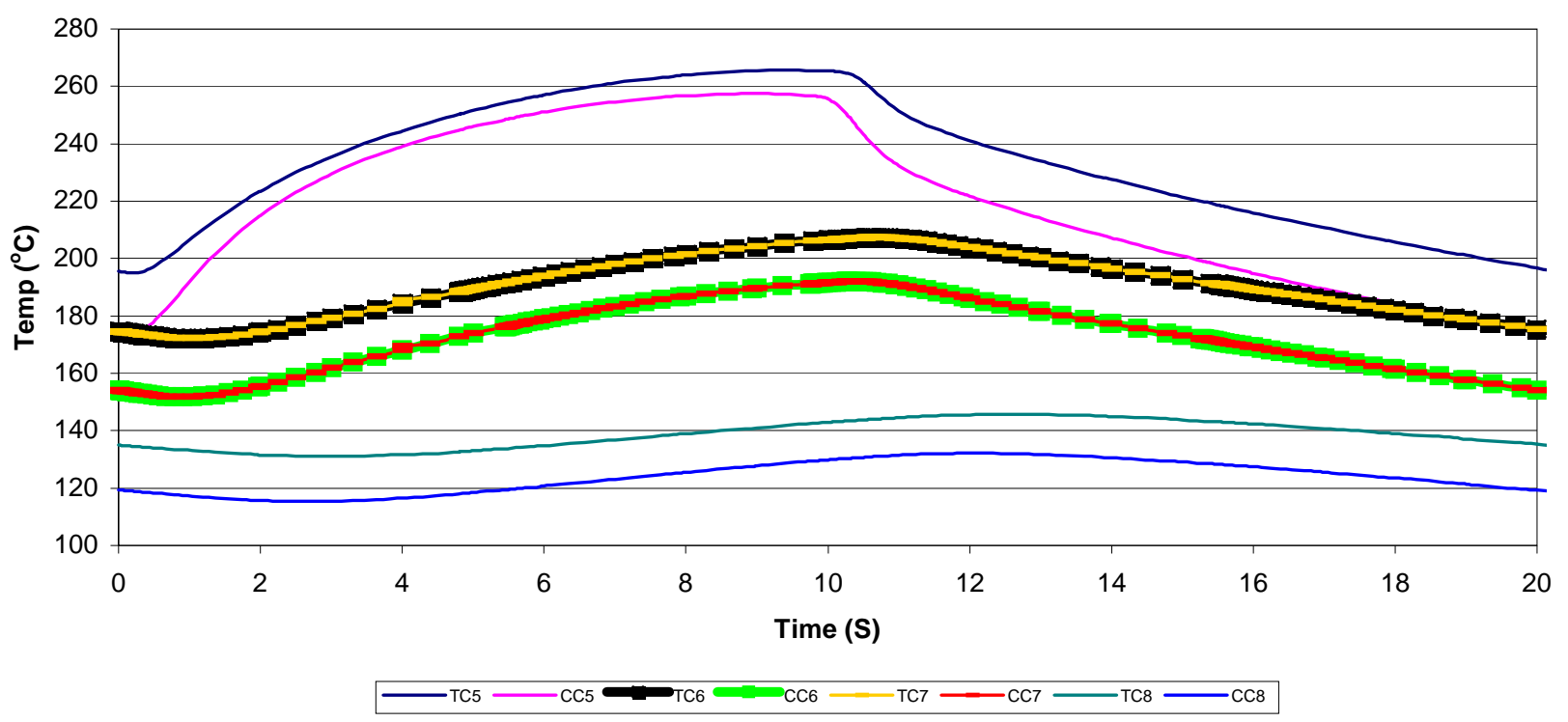

Figure 14 Traditional cooling (TC) verses conformal cooling (CC) (thermocouples 5-8)

\subsection{Results From Casting}

The results from both the traditional and conformal cooled tool inserts were the same. During the casting trials the components were visually examined for signs of a burst biscuit. In both the traditionally and conformally cooled inserts the solidification time could be reduced from 3.5 seconds down to 1 second before signs of a burst biscuit occurred. The lowest time before failure of the biscuit and casting was 0.7 seconds. Failure was determined the biscuit being semi molten and separating from the runner/casting during ejection. 


\section{DISCUSSION}

The Magmasoft simulation does not show an improved solidification time of the casting using the conformal cooled design, shown in Figure 13. The conformally cooled design however, is approximately $20^{\circ} \mathrm{C}$ cooler than the traditionally cooled insert, shown in Figure 14 .. The two simulations show little difference in the cooling performance of the channel designs.

This was verified by the casting trials, proving that the simulation is accurate at predicting solidification rates. It is clear that the design of a conformal cooling channel is critical since both the simulation and physical casting experimentation showed no reduction in solidification time.

The casting trials however, showed a discrepancy in the simulated time for the biscuit to reach solidification since the die could be opened at 1 second with no signs of a burst biscuit. The simulated thermal images Figure 11\& Figure 12 show the biscuit taking 9-10 seconds to reach solidification. This could be due to insufficient or incorrectly placed theoretical thermocouples. The casting trial show that the outermost surface of the biscuit formed a solidified aluminium skin containing the remaining solidifying aluminium inside the it. This allowed the die to be opened at 1 second. Below 0.7 seconds the skin fails creating a burst biscuit.

Although the conformal cooled channel had $1 \frac{1 / 2}{2}$ times the surface area and volume it evidently was not enough to remove the heat. 


\section{CONCLUSIONS}

The results showed that the simulation was accurate at predicting no differences between the channel designs. This was verified by the casting trials. This proves that by simply increasing the length of a channel does not necessarily improve cooling performance in a aluminium pressure die casting tool.

The simulation and casting trials do differ in how solidification takes place in the biscuit area. This area is the last area to solidify, as you would expect. However, the casting trials showed the die could be opened after one second with no signs of a burst biscuit. The simulation begs to differ. It clearly shows the biscuit edges still solidifying after 9-10 seconds. If this were the case the die could not have been opened at 1 second.

The research has outlined the importance of theoretical thermocouple placement and conformal cooling geometry and placement.

The second stage of this research will be to conduct further computational fluid dynamics simulations with different conformal cooling channel designs to improve the cooling of the biscuit area. From this data the most efficient conformal cooling design will be manufactured and the simulated results validated by casting trials. 


\section{ACKNOWLEDGEMENTS}

The authors would like to thank the following for supporting this work:

Foresight Vehicle Programme

The Engineering and Physical Sciences Research Council (EPSRC)

Delcam International

Dyson Ltd

Kemlows Die Casting Products Ltd for their support and casting trials.

MAGMA for running the thermal the finite element simulations.

\section{REFERENCES}

1. Wayde R. Schmidt, Ronald D. White, Connie E. Bird, Joseph V. Bak, Conformal cooling vs. conventional cooling: an injection moulding, case study with 3-dimensional printing. Solid Freeform and Additive Fabrication, Materials Research Society Publications, Volume 625, April 24-26, 2000, pages 51 - 56, ISBN: 1-55899-533-1

2. Dickens P.M. Rapid Prototyping - Past, Present \& Future. Journal of The Institute of Engineering Designers, January 1999, pages 12-15, ISSN 0013-7858

3. Xu-X, Sachs E., Allen S. The design of conformal cooling channels in injection moulding tooling, Polymer Engineering and Science, Volume41, July 2001, pages 1265-1279

4. Halford B. Rapid Tooling, Journal of the Institute of Engineering Designers May 1999, pages 4-6, ISSN 0013-7858

5. Obikawa T. Sheet Steel Lamination for Rapid Manufacturing, Journal of Materials Processing Technology, Volume 89-90, 1999, pages 171-176

6. Xiaorong Xu, Emanuel Sachs, Samuel Allen, The design of conformal cooling channels in injection mould tooling, Polymer and Engineering Science, July 2001, Volume 41, Number 7 , pages $1265-1279$ 